\title{
A divulgação de conhecimentos através de CDs sobre veículos elétricos. Experiência de um projeto de extensão que propiciou implantar um laboratório de sistemas de propulsão veicular Knowledge dissemination through CDs about electric vehicles. An extension project experience that enabled the implementation of a vehicular propulsion system laboratory
}

\section{Introdução}

A importância dos veículos elétricos se justifica nos dias atuais como alternativa aos danos causados ao meio ambiente pelo setor de transportes que utiliza maciçamente combustíveis fósseis. No Brasil, segundo o Balanço Energético Nacional de 2008, este aspecto é bastante crítico tendo em vista a prevalência quase que exclusiva do modo rodoviário neste setor, acarretando 88,3 \% das emissões de $\mathrm{CO}_{2}$ (dióxido de carbono) perante os modais marítimo, aeroviário e ferroviário com um impacto considerável sobre as mudanças climáticas. Também a qualidade do ar dos centros urbanos é bastante prejudicada já que cerca de $80 \%$ da população se concentra nestas áreas. As emissões de poluentes atmosféricos nos seis maiores centros urbanos do país custam, por ano, pelo menos $\mathrm{R} \$ 2,3$ bilhões de reais à sociedade brasileira em decorrência de mortes, tratamento de enfermidades, ausências ao trabalho, etc., de acordo com resultados de estudos do Professor Paulo Saldiva da Universidade de São Paulo - USP publicados, em 2008, pela Associação Brasileira do Veículo Elétrico - ABVE da qual a UERJ é fundadora. Em contraste, somente $1 \%$ da energia elétrica produzida no Brasil é usada nos meios de transporte, mesmo tendo mais de $70 \%$ da eletricidade oriunda de geração hidráulica e um enorme potencial inexplorado, em termos de fontes de origem solar e eólica. Um aspecto importante refere-se à avaliação da eficiência energética do sistema de produção e reabastecimento do veículo à combustão interna convencional que apresenta, em termos de rendimento deste processo, desde a prospecção até a roda de tração um valor inferior ao do veículo elétrico, que é conectado à rede de geração e de distribuição para a recarga das suas baterias. Estas análises, conhecidas na literatura técnica como "well to wheel evaluation" 1 ,
Luiz Artur Pecorelli Peres', Cleiton Magalhães Freitas ${ }^{2}$

\section{Resumo}

O Grupo de Estudos de Veículos Elétricos - GRUVE foi fundado na Faculdade de Engenharia da UERJ em setembro de 2001. A sua missão inclui disseminar conhecimentos à sociedade e o seu primeiro projeto foi produzir e divulgar o CD "Veículos Elétricos: Benefícios Ambientais e Energéticos" cujo lançamento ocorreu na Semana de Meio Ambiente da UERJ em 2003. Diversas entidades, tais como escolas, organizações e empresas foram beneficiadas com palestras, cursos e workshops sobre veículos elétricos utilizando este CD como tutor, com o qual são agraciadas com exemplares para o seu acervo. Alunos da UERJ vêm recebendo treinamento sobre este tema e a sua participação é decisiva nas atividades do GRUVE. O presente trabalho mostra como este projeto de extensão desencadeou parcerias que possibilitaram a realização de pesquisas e a obtenção de recursos financeiros. A implantação do Laboratório de Sistemas de Propulsão Veicular e Fontes Eletroquímicas LSPV se tornou possível e com isto novos conhecimentos se incorporaram ao projeto original propiciando a elaboração de um novo CD "Veículos Elétricos Conquistam as Ruas do Brasil". Com isto estabeleceu-se um processo dinâmico em que a pesquisa e a extensão se renovam. No texto são apresentados a metodologia, os resultados e conclusões desta experiência.

Palavras-chaves: Veículos elétricos; Projeto de extensão; Meio ambiente; Energia

Área Temática: Tecnologia e Produção Linha da Extensão: Desenvolvimento tecnológico

Professor Adjunto da Faculdade de Engenharia da UERJ. Autor Principal e Coordenador do Projeto de Extensão.

E-mail: lapp_uerj@yahoo,com.br

2 Estudante de Engenharia Elétrica da UERJ. Autor Colaborador, Revisor e Bolsista do Projeto de Extensão. 
permitem apontar o Brasil como um dos países mais atrativos para a introdução de veículos elétricos nos meios de transporte.

Estes argumentos justificam a necessidade de desenvolvimento de pesquisas e estudos dedicados à maior penetração da tecnologia veicular elétrica. No exterior, tem sido intensa a soma de recursos investidos nesta área e diversas montadoras de porte nos Estados Unidos da América (EUA), Europa e Ásia anunciam para os anos vindouros, a partir de 2011, o lançamento de modelos de veículos elétricos exclusivamente a bateria. Destaca-se que os veículos híbridos elétricos desde o início desta década já haviam alcançado recordes de venda nos EUA. Este cenário foi intensificado com o anúncio do Presidente Obama dos EUA, destinando 2,4 bilhões de dólares em investimentos a este setor, conforme noticiado pela secretaria de imprensa do governo americano, em agosto de 2009.

No Brasil, há falta de políticas públicas para vencer as barreiras institucionais de caráter tributário de forma a facilitar a penetração destes meios de transporte. Esta carência impede que se introduza, por exemplo, o veículo elétrico híbrido "flex-fuel" o que representa uma perda de oportunidade surpreendente. Ao mesmo tempo em que as motocicletas a combustão interna saem das montadoras sem catalisadores, verifica-se a existência de impostos altíssimos que inibem a sua produção com propulsão elétrica ${ }^{2}$. Fatos como estes fizeram com que se constatasse a enorme lacuna na divulgação de conhecimentos sobre tecnologia veicular elétrica no Brasil. Há poucas teses de mestrado e doutorado e raros são os livros escritos por autores brasileiros sobre veículos elétricos ${ }^{3}$. No tocante aos eventos nacionais, estes também são escassos, limitando-se, quase que exclusivamente, à ABVE a sua organização. No máximo, as mudanças que são perceptíveis nos últimos dois anos, têm sido um maior volume de reportagens sobre estes temas destinados ao campo da informação, deixando, assim, um enorme vazio no campo do conhecimento.

A UERJ, desde 1990, reconhecendo os aspectos estratégicos deste tema vem se destacando na publicação de trabalhos e na elaboração de projetos, tendo em vista o seu potencial de benefícios sociais e econômicos. Além disto, como se trata de assunto que abrange saberes e com- petências multidisciplinares, abre-se um enorme campo de trabalho e inserção profissional. Para reunir melhor estes conhecimentos foi fundado, em 2001, o Grupo de Estudos de Veículos Elétricos - GRUVE, vindo a se tornar uma entidade reconhecida como Projeto Especial pela Faculdade de Engenharia da UERJ, conforme declaração do seu Conselho Departamental número 22/2005 de 10/05/2005, sendo o seu primeiro projeto a produção e a divulgação do CD "Veículos Elétricos: Benefícios Ambientais e Energéticos" ${ }^{\text {"4 }}$ cujo lançamento ocorreu na Semana de Meio Ambiente da UERJ, em 2003. Diversas entidades, entre elas instituições de ensino, universidades, organizações e empresas vêm sendo beneficiadas com palestras, cursos e workshops sobre veículos elétricos e agraciadas com exemplares deste CD para o seu acervo. O CD serve de tutor para estes eventos e, para a sua realização, os alunos da Faculdade de Engenharia recebem treinamento analítico e experimental sobre os assuntos abordados.

O presente trabalho mostra como este projeto de extensão desencadeou parcerias que possibilitaram a realização de pesquisas e até mesmo a obtenção de recursos financeiros. Uma decorrência marcante refere-se à implantação, no início de 2007, do Laboratório de Sistemas de Propulsão Veicular e Fontes Eletroquímicas - LSPV no Centro de Ciência e Tecnologia - CCT da Faculdade de Engenharia, no bairro Imperial de São Cristóvão, no Rio de Janeiro. Com esta instalação tornou-se possível ampliar de maneira mais acelerada novos conhecimentos que vêm se incorporando ao projeto original. Isto propiciou a elaboração de um outro CD denominado "Veículos Elétricos Conquistam as Ruas do Brasil"5, em edição bilíngue, portuguesa e inglesa, que descreve por intermédio de textos e vídeos, trabalhos pioneiros realizados pela UERJ. Vem se estabelecendo, assim, um processo dinâmico em que a pesquisa e a extensão se renovam mutuamente. Nos itens que se seguem são apresentados a metodologia, os resultados e as conclusões desta experiência.

\section{Metodologia}

O projeto "Produção e Divulgação de CDs sobre Veículos Elétricos" está vinculado à Sub-Reitoria de Extensão e Cultura SR-3 da UERJ por intermédio do Departamento de Extensão DEPEXT que coordena e supervisiona as ações 
que lhe são pertinentes pelas unidades acadêmicas e administrativas da Universidade, inclusive, no provimento de bolsas de auxílio aos alunos engajados. Este projeto iniciou seus trabalhos em meados de 2002, um ano após a fundação do Grupo de Estudos de Veículos Elétricos, em que se concretizam as práticas de extensão.

A metodologia para a disseminação de conhecimentos sobre tecnologia veicular elétrica, meio ambiente, energia e transporte é aplicada tanto internamente como externamente à UERJ considera duas vertentes. A primeira tem como alicerce as pesquisas realizadas e das quais se retira o conhecimento a ser divulgado. A segunda vertente se baseia nas atividades a seguir:

- Produção de CDs educativos tendo como referência a área de pesquisa "Análise e Desenvolvimento de Sistemas de Propulsão Veicular Elétrica", à qual o Grupo de Estudos de Veículos Elétricos se dedica.

- Busca de patrocínios e apoios para a produção dos CDs e estabelecimento de equipes que se engajam nos trabalhos de propulsão veicular elétrica.

- Disseminação do conteúdo do CDs através de cursos, conferências e workshops gratuitos ministrados às entidades interessadas que recebem exemplares dos CDs para o seu acervo. Há uma agenda com as datas disponíveis para marcação destes eventos e nestas oportunidades são realizados avaliações, debates e conversações que propiciam o estabelecimento de intercâmbios técnicos e parcerias.

- Produção de panfletos com a descrição do projeto e o contato para a entidade interessada inscrever-se no calendário das atividades de extensão.

- Realização de pesquisas, projetos e estudos no âmbito do LSPV e GRUVE com os quais se busca identificar conteúdos para elaboração de novos CDs.

- Introdução de atividades de extensão com mecanismos pedagógicos de avaliação.

É importante observar que, durante os primeiros anos de atuação do projeto a busca inicial do público se concentrou em solicitações de apresentação de palestras com foco no estado da arte da tecnologia veicular elétrica e as suas oportunidades. Entretanto, com o passar do tempo constatou-se a necessidade de acrescentar de forma concomitante alternativas para atender estas novas demandas que foram surgindo e, assim, oferecer a possibilidade de um maior grau de aquisição de conhecimentos acompanhados da sua respectiva aferição. A análise desta questão foi bastante discutida no âmbito do projeto e com outros setores da UERJ. A opção que se mostrou mais atrativa, foi a montagem de um curso de extensão, aprovado pela SR-3, sobre sistemas de propulsão veicular elétrica, utilizando os CDs, em que os aspectos de avaliação pedagógica estão intrinsecamente considerados. Deste modo, o projeto passou a dispor de dois seguimentos de atuação: o de caráter informativo e o de caráter educacional, também gratuito. Outros aprimoramentos se referem à inclusão de novos espaços como, por exemplo, o do LSPV o que possibilita agregar às apresentações e aos cursos experiências e ensaios com veículos elétricos.

Faz-se necessário destacar o motivo da escolha do CD como meio de divulgação atrelado ao projeto. $\mathrm{O} C D$ constitui um produto que possui direitos autorais e apresenta diversas possibilidades didáticas, inclusive de autoaprendizado. Sendo assim, oferece peças de multimídia com ilustrações, animações, vídeos e os tradicionais textos de trabalhos publicados. Os conhecimentos contidos no CD podem ser acessados e consultados individualmente ou em grupo. Além disto, o custo de reprodução e a facilidade de transporte atendem aos orçamentos disponíveis. Ao serem ofertados às entidades beneficiadas fica perfeitamente claro o respeito à autoria dos conteúdos sem que haja restrições à reprodução do $\mathrm{CD}$. A agregação das palestras, cursos e workshops são fundamentais, pois, em geral, permitem conhecer as indagações das entidades interessadas a respeito da tecnologia veicular elétrica e o estabelecimento de modos de colaboração e parcerias que podem, inclusive, promover o desenvolvimento de pesquisas com suporte financeiro. Para finalizar este item serão descritos os CDs já editados.

O primeiro projeto do GRUVE foi concebido na área de extensão acadêmica, com a produção do CD: "Veículos Elétricos: Benefícios

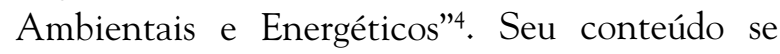
dedica, através de textos e ilustrações, a explicar conceitos, o funcionamento de componentes, da- 
dos técnicos e ainda incluindo alguns artigos do autor sobre veículos elétricos, justamente com o intuito de preencher a lacuna existente na sociedade sobre o conhecimento dos aspectos gerais da tecnologia veicular elétrica. A elaboração deste CD contou com a participação de alunos de engenharia da UERJ. Foi imprescindível o patrocínio de diversas empresas, a saber: Eletrobrás Centrais Elétricas Brasileiras, Eletra, Furnas Centrais Elétricas S.A, Ingersol Rand do Brasil, Jacto Máquinas Agrícolas Jacto S.A e Quattri Design Consultoria, bem como o apoio da Associação Cultural e de Pesquisa Noel Rosa da UERJ, na administração de recursos e do setor contábil de todo o projeto do CD. Seu lançamento ocorreu na Semana do Meio Ambiente da UERJ em 7 de junho de 2003. A Figura 1 que se segue exibe a capa e a contra capa deste CD.
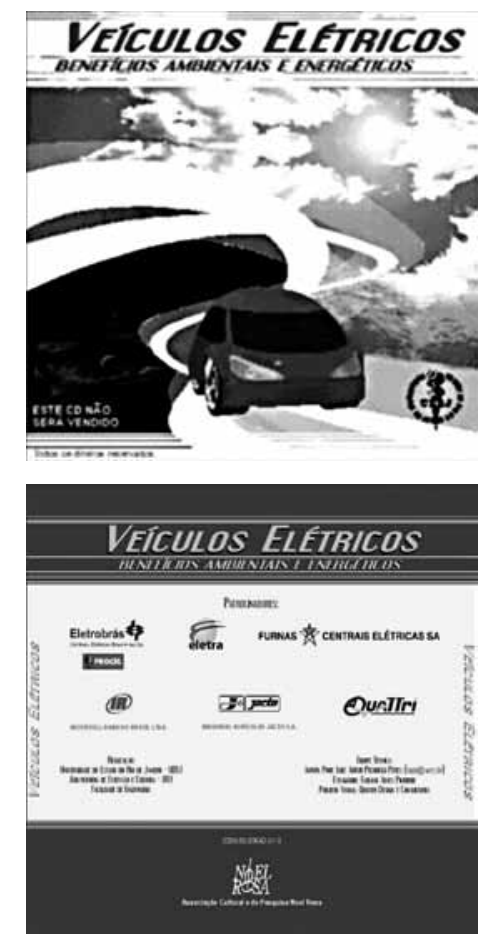

Figura 1 - Capa e Contra Capa do CD "Veículos Elétricos: Benefícios Ambientais e Energéticos"

No que tange à execução do CD houve diversos cuidados pedagógicos quanto à sua navegação. O primeiro nível de acesso apresenta as seguintes opções: Introdução, Homenagem, Patrocínios e Apoios, Veículos Elétricos, Energia e Ambiente, Consultas e Saída. Na parte do CD denominada Veículos Elétricos, consta de uma série de abordagens, isto é, conceitos, tipos, componentes, simulação, normas e dados técnicos. Especial atenção foi dedicada ao Meio Ambiente e Energia reservando-se ainda uma seção dedicada a Consultas da qual integram uma biblioteca, entidades e associações. Uma atenção especial é dedicada aos Eventos, pois se referem àqueles ocorridos em 2002, no âmbito do calendário de realizações da Sub-Reitoria de Extensão e Cultura da UERJ, isto é, Semana de Meio Ambiente, UERJ sem Muros e a Mostra de Extensão. Em todos eles o GRUVE esteve presente, inclusive, com uma marcante e pioneira exposição no campus da UERJ: "Veículos Elétricos: Caminho para Diminuir a Poluição do Ar".

Estas iniciativas de extensão deram ensejo à aprovação de trabalhos da UERJ, tanto no Brasil, como no exterior, nos quais este projeto foi apresentado ${ }^{6,7}$. Neste ponto, houve a formação de uma parceria com o Instituto Nacional de Eficiência Energética - INEE e assim, em conjunto, foi fundada em 2006, a Associação Brasileira do Veículo Elétrico - ABVE. Ao todo, desde estes primeiros passos, foram organizados pelo INEE e, mais recentemente, com a ABVE, dez eventos nacionais sobre veículos elétricos nos quais a UERJ com seus alunos e professores tiveram sempre destacada participação. Merece menção o Primeiro Encontro Luso-Brasileiro sobre Tecnologia Veicular Elétrica, no Blue Tree Convention Ibirapuera, São Paulo SP, em 17 de Maio de 2005, organizado pelo GRUVE com apoio do INEE. O intercâmbio técnico estabelecido possibilitou propor em conjunto o projeto de pesquisa "Avaliação de Desempenho de Veículos Elétricos Atuando em Frotas de Empresas Distribuidoras de Energia Elétrica" cuja execução foi aprovada em 2006 pela Agência Nacional de Energia Elétrica - ANEEL, tendo como empresa parceira a Ampla Energia e Serviços S.A.. Vale mencionar que esta foi a primeira vez que a ANEEL aprovou a inclusão do tema veículo elétrico no seu elenco de projetos de pesquisa.

Esta iniciativa proporcionou o ingresso de recursos financeiros da ordem de quatrocentos mil reais e foi determinante para a realização de uma das metas e sonhos do GRUVE, isto é, a implantação do Laboratório de Propulsão Veicular e Fontes Eletroquímicas - LSPV localizado no Centro de Ciência e Tecnologia da Faculdade de Engenharia - CCT, no final de 2007 e que está integrado às instalações do Curso de Pós-Graduação em Engenharia Mecânica. O local onde era originalmente um depósito foi transformado em 
um Laboratório que conta com instrumentação apropriada para a realização de análise de desempenho de veículos elétricos, inclusive, dispondo de conexão com painéis fotovoltaicos para a realização de ensaios de recarga com energia solar. Uma outra peculiaridade deste Laboratório é que a sua concepção busca atender as novas tendências da área automotiva em que a engenharia mecânica, a elétrica e a eletrônica devem conviver num mesmo espaço. Assim, no ambiente onde se pesquisa e se introduz a tecnologia veicular elétrica, alunos e professores destas modalidades desenvolvem um profícuo trabalho e intercâmbio.

No LSPV, atua também o projeto, atualmente denominado "Baja SAE", que consiste numa competição entre equipes de estudantes de graduação de cursos de engenharia organizada pela SAE Brasil - Sociedade de Engenheiros da Mobilidade cujo objetivo é projetar, construir e demonstrar o desempenho de um veículo de pequeno porte.

A Figura 2 apresenta fotos do local onde funciona o LSPV antes e depois da sua implantação.

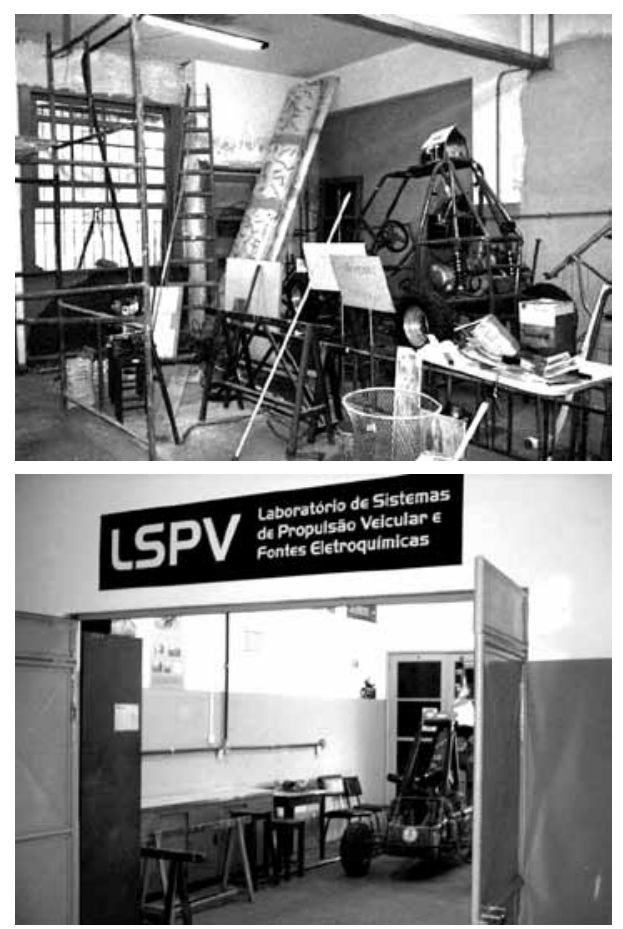

Figura 2 - Foto do Local Antes e Depois da Implantação do LSPV no Centro de Ciência e Tecnologia da Faculdade de Engenharia da UERJ

Com isto tornou-se possível consolidar o ciclo de atividades em que o projeto de extensão proporciona o desenvolvimento da pesquisa e esta os recursos para os trabalhos experimentais.
O ciclo seguinte consistiu, a partir da pesquisa em parceria com a AMPLA, na elaboração do CD "Veículos Elétricos Conquistam as Ruas do Brasil". De fato, este projeto proporcionou a elaboração de uma razoável quantidade de experimentos com veículos elétricos. Além dos aspectos metodológicos algumas deles por serem pioneiros ${ }^{8}$ determinaram o registro em vídeo dos processos de execução. Com o término do projeto de pesquisa em 2008 deu-se início à elaboração deste segundo CD com base nos conhecimentos adquiridos na pesquisa.

Este CD se destaca como uma publicação multimídia que contêm as cenas de um teste com um veículo elétrico (Palio Week End) pela primeira vez atravessando pela Ponte Presidente Costa e Silva, conhecida como Ponte Rio - Niterói, a Baía da Guanabara, em 5 de maio de 2008. O trajeto foi iniciado nos escritórios da AMPLA, em Niterói, terminando no LSPV, em São Cristóvão. Logo no primeiro nível de acesso é apresentada a possibilidade de escolha entre a versão em português e a versão em inglês.

No segundo nível de acesso, são exibidas as abas: Introdução, Realização, Agradecimentos, Vídeos, Resultados, Áreas de Interesse, Contatos e Sair. Através destas abas navega-se em todas as seções da publicação.

A Figura 3 ilustra o segundo nível de navegação do CD que constitui a tela principal.

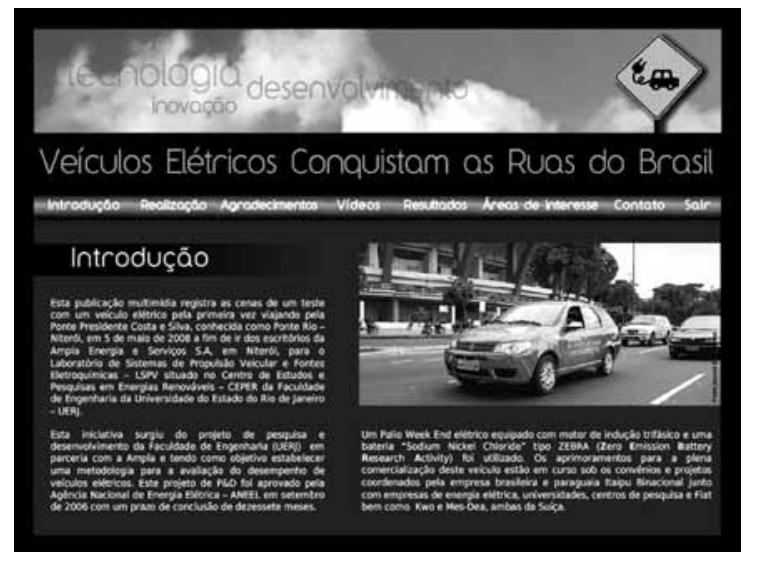

Figura 3 - Tela Principal do CD

"Veículos Elétricos Conquistam as Ruas do Brasil"

A aba "Introdução" apresenta um breve resumo do projeto de pesquisa realizado em parceria com a AMPLA e sob aval da ANEEL. Na aba "Realização" é mencionada a autoria do CD e as referências bibliográficas utilizadas, constando também uma seção de agradecimentos. Na seção 
"Vídeos", são exibidos quatro vídeos. Os dois primeiros vídeos exibem respectivamente o trajeto mencionado pela ponte Rio-Niterói e a chegada do veículo ao LSPV. Em seguida, há um vídeo que relata uma seção de testes de recarga realizados no LSPV com o Palio "Week End" Elétrico e logo depois um outro vídeo ilustra cada um dos componentes do veículo. Por fim, são apresentados slides com fotos do veículo elétrico e de seções de testes realizados como o mesmo na UERJ. A seção "Resultados" descreve em detalhes os testes executados com o veículo elétrico referente ao seu trajeto desde Niterói até o LSPV passando pela ponte Rio - Niterói. Os resultados obtidos são comparados com aqueles de um veículo a combustão interna similar e mostram os benefícios da utilização do veículo elétrico. As áreas de desenvolvimento do LSPV bem como os contatos e sua localização são exibidos nas respectivas seções "Áreas de Interesses" e "Contato". Ao acessar a aba "Sair" o usuário é encaminhado para uma seção contendo uma mensagem do autor e a opção Sair. A Figura 4 apresenta a capa e a contra capa do CD descrito:

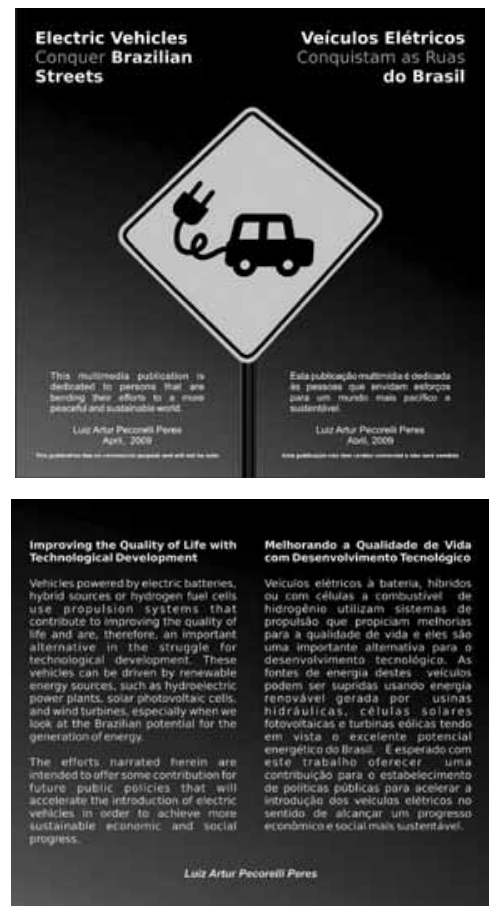

Figura 4 - Capa e Contra Capa do CD "Veículos Elétricos Conquistam as Ruas do Brasil"

\section{Resultados e Discussão}

Neste item pretende-se destacar os resultados do projeto de extensão aqui abordado.
O primeiro $\mathrm{CD}$ produzido e divulgado pelo projeto de extensão contou com uma edição apoiada por patrocinadores e com isto cerca de 1800 cópias foram distribuídas no período de 2003 a 2009, sendo que as trezentas primeiras foram enviadas por Correio para entidades cadastradas antes do seu lançamento. Tendo em vista que exemplares restantes do CD foram distribuídos gratuitamente, sendo uma boa parte mantida em acervos e bibliotecas abertas à consulta, o universo de pessoas que passaram a entrar em contato com os conhecimentos desenvolvidos na UERJ neste assunto ultrapassa atualmente a dez mil, mesmo considerando de forma conservadora, que para cada $\mathrm{CD}$ a sua divulgação espontânea atingisse em média seis pessoas. A este conjunto devem-se acrescentar os assistentes das palestras, cursos e workshops realizados que coincidem com os meses dos períodos letivos. Com isto, sendo a média de assistentes da ordem de quarenta, podendo alcançar a cem no caso de um workshop, contabilizam-se três mil participantes que interagiram a respeito dos conceitos, das inovações e dos benefícios da tecnologia veicular elétrica para a sociedade.

Com a edição do novo CD "Veículos Elétricos Conquistam as Ruas do Brasil", cujo conteúdo focaliza experimentos em centros urbanos, constata-se um interesse maior despertado em torno do projeto de extensão. Em síntese, verifica-se que internamente, na UERJ, uma maior quantidade de alunos vêm buscando no GRUVE temas para o desenvolvimento de pesquisas e encontram nos CDs já produzidos farto material de referência. A título de exemplo são mencionadas algumas entidades internas e externas à UERJ beneficiadas com o projeto de extensão: CAp-UERJ Instituto de Aplicação Fernando Rodrigues da Silveira, Instituto de Química, Escola Superior de Desenho Industrial - ESDI, Escola Técnica do Arsenal de Marinha, Escola Técnica Ferreira Viana, Universidade Federal de Santa Catarina, Furnas Centrais Elétricas S.A, Universidade Gama Filho, COPPETEC/UFRJ, Operador Nacional do Sistema Elétrico - ONS, etc.

Um resultado que merece ser mencionado entre as experiências proporcionadas por este projeto de extensão surgiu do convite do Núcleo de Tecnologia Automobilística - NTA do Centro Federal de Educação Tecnológica Celso Su- 
ckow da Fonseca - CEFET / RJ para a realização de um mini-curso sobre veículos elétricos para alunos e professores desta instituição. Em consequência, houve o estabelecimento de uma parceria com a qual foi realizado um projeto inovador de conversão de uma Kombi para tração elétrica com patrocínios da WEG, SATURNIA e apoios da Light Serviços de Eletricidade S.A, da Fundação Rotária para a Educação do Trabalho, do Rotary Internacional e da ABVE. Este desenvolvimento inédito inclui ações de extensão, pois, um dos objetivos primordiais é a participação do veículo em exposições e demonstrações para o público e também servir de laboratório para testes de novos componentes. A conclusão da montagem da Kombi Elétrica permitiu que o veículo participasse do evento internacional Challenge Bibendum 2010, no Riocentro, recebesse um troféu e desfilasse pela orla marítima da Praia do Flamengo ao lado de outros expositores. Este evento teve uma enorme divulgação pela mídia no Brasil e no exterior.

Acrescente-se que cinco professores do CEFET-RJ vieram a frequentar cursos de pós-graduação de Engenharia Mecânica da UERJ o que permitiu a conclusão de dissertações de mestrado, uma delas dedicada à metodologia de conversão de veículos a combustão interna para tração elétrica orientada pelo coordenador do projeto de extensão aqui descrito.

A Figura 5 apresenta uma foto da Kombi convertida para tração elétrica.

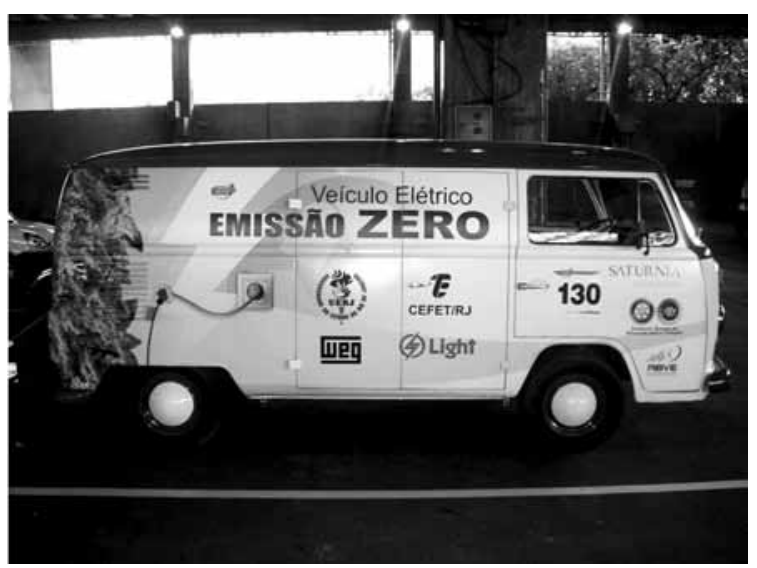

Figura 5 - Foto da Kombi Convertida para Tração Elétrica pela UERJ e CEFET-RJ no Pavilhão de Expositores do Challenge Bibendum 2010 no Riocentro

\section{Conclusão}

O projeto de extensão da produção e divulgação de CDs sobre a tecnologia veicular elétrica serviu de alavanca para projetos de pesquisa que por sua vez incorporam novos conhecimentos ao projeto de extensão. Como os recursos do projeto de extensão são obtidos por meio de patrocínios, as despesas diretas para a UERJ se limitam às bolsas para os estudantes de engenharia. Pode-se concluir que há assim uma alta relação benefício-custo.

Um retorno considerável vem sendo alcançado pelo expressivo número de estudantes, profissionais e o público em geral, que passa a ser inserido nos conhecimentos sobre a tecnologia veicular elétrica e seus benefícios. Decorre daí o estabelecimento de canais de diálogo entre a UERJ e as entidades interessadas de forma a propiciar intercâmbios técnicos, parcerias e convênios para promover a pesquisa e a difusão do uso dos veículos elétricos em âmbito estadual e nacional.

Constata-se que o projeto contribui com impactos positivos para a formação do estudante que nele se engaja e diversas publicações vêm sendo produzidas.

\section{Agradecimentos}

À direção da Faculdade de Engenharia e à Sub-Reitoria de Extensão e Cultura da UERJ, aos patrocinadores dos projetos citados. À dedicação e a excelência com que foi elaborada a programação visual dos CDs pelo designer Nelson de Faria Peres. Em especial, ao apoio e colaboração inestimáveis do Professor Mauricio José Ferrari Rey da UERJ, in memoriam.

\section{Referências}

1. LARMINE, James; Lowry, John, Electric Vehicle Technology. 1. ed. West Sussex: John Wyley \& Sons Ltd., 2003. 296 p.

2. BOTTURA, Celso P.; BARRETO, Gilmar. Veículos Elétricos. 1. ed. Campinas: UNICAMP, 1989. 285 p.

3. NUNES, Antonio Jr. . Alta Carga Tributária Desestimula Comercialização de Carros Elétricos. Revista Híbrida, Rio de Janeiro, ano 1, n. 1, p. 35-37, Julho/ Agosto. 2008.

4. PECORELLI PERES, Luiz A. . Veículos Elétricos: Benefícios Ambientais e Energéticos. Rio de Janeiro: Associação Cultural e de Pesquisas Noel Rosa, 2003. CD-ROM. 
5. PECORELLI PERES, Luiz A. Veículos Elétricos Conquistam as Ruas do Brasil. CD, edição bilíngüe, Rio de Janeiro: Editor-Autor, 2009. ISBN: 978-85910201-0-2.

6. PECORELLI PERES, Luiz A.; PINHEIRO, Fabiano Alves; SILVA, Mariana Dias. Disseminação dos Conhecimentos sobre os Benefícios da Utilização de Veículos Elétricos pela Sociedade e as suas Relações com o Meio Ambiente e a Energia. Interagir: Pensando a Extensão, n. 6, Agosto/Dezembro. 2004.

7. PECORELLI PERES, Luiz A. Dissemination of Electric Vehicle Technology Through an Educational CD. Evaluation and Recent Experience in Brazil. In: EUROPEAN ELE-DRIVE TRANSPORTATION CONFERENCE \& EXHIBITION ON URBAN SUSTAINABLE MOBILITY IS POSSIBLE NOW BATTERY,HYBRID AND FUEL CELL ELECTRIC, 2004, Estoril. Portugal, Estoril: CD AVERE- APVE, 2004.

8. PEÇANHA, M. Lellis P.; PECORELLI PERES, Luiz A.; Experiência de Recarga de Moto Elétrica Através de Rede Elétrica Local e de Célula Fotovoltaica - Análise Comparativa Sob o Ponto de Vista de Geração de Harmônicos. In: SEMINÁRIO E EXPOSIÇÃO DE VEÍCULOS ELÉTRICOS A BATERIA, HIBRIDOS E DE CÉLULA COMBUSTÍVEL 5., 2007, Rio de Janeiro. Rio de Janeiro: INEE e ABVE, 2007.

\section{Abstract}

The Electric Vehicles Studies Group (GRUVE) was founded at the Engineering School of UERJ in September 2001. Its mission includes disseminating knowledge to society and its first project was to produce and promote the $C D$ "Electric Vehicles: Environmental and Energetic Benefits", whose launch was held at UERJ Environment Week in 2003. Various entities such as schools, organizations and companies were benefited from lectures, courses and workshops about electric vehicles having this $C D$ as tutor, which received free copies for their libraries. UERJ students have been trained on this subject and their participation is crucial in the GRUVE activities. This article shows how this extension project promoted partnerships that rendered financial funding for research projects. This funding was invested the Vehicular Propulsion Systems and Electrochemical Sources Laboratory - LSPV at UERJ which is now a reality. New researches were developed enabling the production of a new educational CD "Electric Vehicles Conquer the Brazilian Streets" in 2009. A dynamic process is in activity in which the research and the knowledge extension are renewed. This text describes the methods, the results and conclusions out of this experience.

Keywords: Electric vehicles; Extension project; Environment; Energy 